\title{
Hierarchical methodology to optimize the design of stand- alone electrification systems for rural communities considering technical and social criteria
}

\author{
Domenech B*ac ${ }^{\text {ac }}$ Ferrer-Martí $\mathrm{L}^{\mathrm{bc}}$, Pastor $\mathrm{R}^{\mathrm{ac}}$ \\ ${ }^{a}$ Department of Management (DOE) \\ ${ }^{\mathrm{b}}$ Department of Mechanical Engineering (DEM) \\ ${ }^{\mathrm{c}}$ Institute of Industrial and Control Engineering (IOC) \\ Universitat Politècnica de Catalunya (UPC); Av. Diagonal 647, 08034, Barcelona (Spain) \\ Contact $(*)$ : bruno.domenech@upc.edu; (+34) 934.016 .579
}

\begin{abstract}
Stand-alone electrification systems based on the use of renewable energies are suitable to electrify isolated rural communities in developing countries. For their design several support tools exist, but they do not cover some of the technical and social existing constraints and they do not consider the project detail. In this context, this research aims to develop a methodology to optimize the design of such systems, combining the wind and solar generation technologies as well as microgrids and individual systems as distribution scheme, and including economical, technical and social considerations. The design methodology is divided in three stages. First, the characteristics of the target community are gathered. Second, the design process is realized in three decision levels, ordered according to the importance of the decisions taken. At each level several electrification alternatives are generated and then the most appropriate is selected. Third, the final solution cost can be optionally tried to be improved, maintaining the decisions previously taken. The design methodology has been applied to a community to show its suitability to assist rural electrification promoters to design socially adapted and sustainable projects.
\end{abstract}

Keywords: design methodology; stand-alone electrification; wind-PV energies; microgrids.

\section{Introduction}

Nowadays around 1.3 billion people lack of access to electricity [1]; mainly in rural areas of developing countries [2]. To electrify this population, systems based on the use of wind and photovoltaic (PV) energies are a suitable option [3]. Both technologies complement to each other and allow attaining a great reliability of supply [4]. Due to the typical dispersion between houses in rural communities, usually individual systems are implemented [5]. As an alternative, projects that combine individual systems with one or more microgrids are increasingly being used, since microgrids have many advantages $[6,7]$. However, this combination entails a higher design difficulty, being necessary to plan the structure and connections of microgrids and to study a good compromise between their extension and possible cost increases when linking points [5].

Additionally, social considerations have proven to be a key issue to consider in the design of electrification projects $[8,9,10]$. For attaining a better projects' sustainability, the way they are carried out needs to be changed promoting high community participation during the design process $[11,12]$. Moreover, when considering several technical options inside a single community (such as wind, PV, microgrids and individual systems) a higher analysis of the social characteristics (as the community organization or the representative authorities) is particularly necessary to respect population preferences, and avoid social conflicts [13]. However, including social considerations in the systems design, in addition to economic and technical ones, significantly adds complexity to the projects' design process. 
Due to the commented reasons, design aid tools are needed to assess the decisionmaking when designing stand-alone wind-PV electrification projects. In this line, a general two-phase process is recommended [14]: first generating a set of efficient solutions or alternatives (Phase 1), utilizing optimization methods, and then selecting the most appropriate one (Phase 2), using multicriteria techniques. Thus, a great accuracy in the problem optimization can be attained and the decision-making can be carried out easily since the problem is known before deciding [15]. For example, OptElDec [16] sizes several technologies to supply isolated microgrids, simulates their performance and ranks them according to quantitative and qualitative criteria. However, the combination of technologies is not allowed and no detail of the electric distribution is offered. SURE $[17,18]$ models different energy options for isolated communities in developing countries and selects the most appropriate according to physical, financial, natural, social and human criteria, using the compromise programming technique. Technologies combination is allowed, but the detail of the distribution and the decisionmaking process are not offered. Finally, Perera et al. [19] combine multiobjective and multicriteria techniques to design wind-PV systems supported by banks of batteries with a great detail of the energy resources, but they neither detail the distribution scheme.

Other works just focus on one of the two phases (alternatives generation or selection). Generally they are adequate for a specific problem but would have limitations if applied to other contexts. For the generation phase (Phase 1), most of the works combine several technologies to meet a specific demand, considering the detail of the energy resources, but without detailing the electric distribution scheme [20, 21, 22, 23, 24]. HOMER [25] and ViPOR [26] are widely used for designing electrification projects in rural areas of developing countries. HOMER designs the generation system, with a great detail of equipment and including many technologies, while ViPOR plans the distribution scheme. However, only one microgrid is allowed and combined with individual systems. Moreover, these works do not consider the social characteristics of the communities and the populations.

For the selection phase (Phase 2), in literature there is a tendency to start from a set of predefined scenarios and aim to choose the most appropriate one considering several criteria. In fact, including several criteria in energy planning is a key factor to attain projects' sustainability $[10,27]$. The process for this selection phase is usually structured in four points [28]: 1) criteria definition; 2) criteria weighting; 3) alternatives evaluation; and 4) results analysis and discussion. Most works partially or completely follow this structure using different multicriteria techniques [22, 29, 30, 31]. Complementarily, to simplify the decision-making in the energy field, Thery \& Zarate [32] propose the usual division in three levels: strategic decisions (high and long-term impact), tactical decisions (moderate and medium-term impact) and operational decisions (low and short-term impact). However, the way as the predefined scenarios are conceived or designed is generally not detailed.

In this context, this research aims to develop a methodology to design stand-alone electrification systems for rural communities, based on hybrid wind-PV energies, combining microgrids and individual systems and considering the detail of economical, technical and social characteristics of population. It is worth to highlight that including other generation technologies could use the same decision process and hierarchical framework. The design methodology is suitable to assist rural electrification promoters, allows studying a great amount of design options in a clear and structured framework 
and obtains solutions that match up end-users preferences. As result the most appropriate size and location of all the equipment to install is obtained, as well as the microgrids, their structure and the individual systems.

The methodology is organized in three stages. First, three assessments have to be realized to gather information about the community and its population. Second, the system design is carried out in three decision levels, ordered according to the importance of the decisions taken. At each level, a set of electrification alternatives is generated, studying a specific characteristic of solutions, and then the most appropriate alternative is selected based on several criteria. Two iterative procedures complement the process to adjust decisions when going in-depth into the problem. Finally, an optional third stage carries out a local optimization process maintaining the decisions previously taken. The functioning of the methodology is finally illustrated through its use by a rural electrification expert to design the electrification system of a community.

The rest of the paper is organized as follows. In Section 2 the technical and social design considerations of the electrification projects are described. Section 3 is the central axis of this work: the proposed methodology for the design of stand-alone electrification systems is presented. In Sections 4 and 5 the two main parts of the methodology (the alternatives generation through a mathematical model and the alternatives selection based on the compromise programming) are explained. In Section 6 the functioning of the methodology is illustrated through its application for a community. Finally, conclusions are summarized in Section 7.

\section{Design considerations}

In this section the stand-alone electrification systems are first technically described. Then the social considerations included in the design of the systems are listed.

\subsection{Technical description}

Fig. 1 shows the scheme of hybrid wind-PV systems generally used to electrify rural communities in developing countries autonomously, which can be divided in two parts [33]: the generation system and the distribution scheme. Regarding the generation part, the electricity is produced by the wind turbines and the PV panels. The controllers protect batteries from overloads and deep discharges that could damage their performance. The batteries store the energy to bridge the gap between generation and consumption. Finally, the inverters transform the direct current leaving batteries into alternate current (more suitable for most electrical appliances). Regarding the distribution part, the electricity from the generation system is distributed to the consumption points (houses, schools, health centers, shops, etc.) individually (if a single point is connected) or with a radial microgrid (if several points are connected). Additionally a meter is installed at each point to control its consumption. 


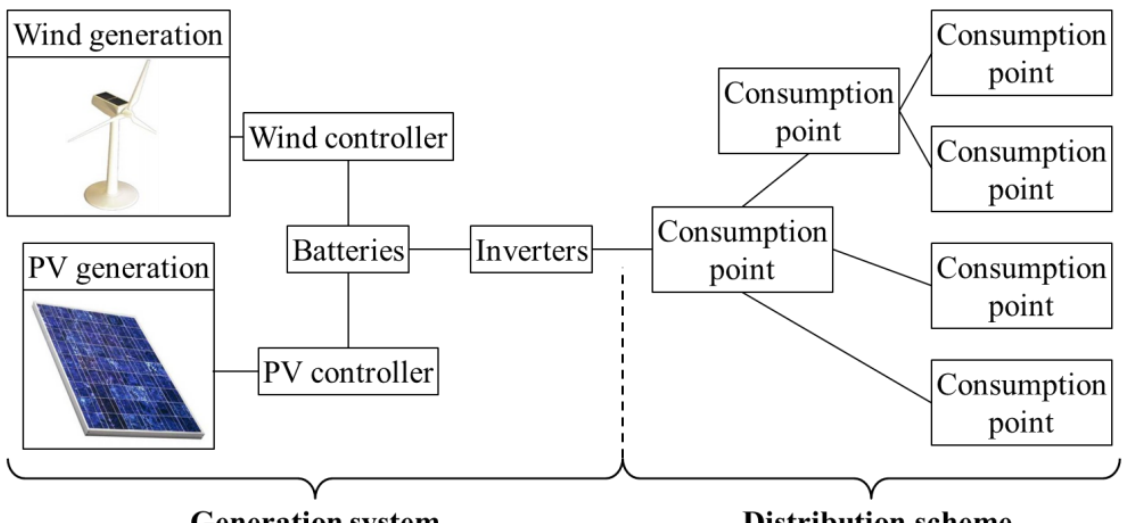

Fig. 1 - Scheme of a hybrid wind-PV system [adapted from 33]

\subsection{Social considerations}

The covered energy uses are a key element to design electrification systems. An excessive supply can unnecessarily raise the project cost while a limited supply can create false expectations among population (non-covering their real needs) [34]. Despite of its importance, the demand has not always been studied in literature, assuming a specific value without a detailed analysis. However determining a demand value is not easy. Moreover, when working with equipment with tiered technical and economical characteristics, the ratio cost per energy produced can be higher or lower depending on the demand. For that reason, it should be interesting to study the cost of a basic energy supply (to cover basic needs) and progressive increases.

Domenech et al. [35] analyze five hybrid wind-PV rural electrification projects, concluding that the management of the system and the adequacy of equipment to endusers are key elements when desiring to design socially adapted, reliable and sustainable installations. In particular, this work proposes to study (Table 1): the configuration of the electric distribution scheme to ease the management of the system and the typology of equipment to improve its adequacy to end-users. Therefore, some design options are proposed to be studied in order to improve the social suitability of projects.

Table 1 - Considerations to ease the management of the system and to improve the adequacy of equipment

\begin{tabular}{|l|l|}
\hline Consideration & Design option proposals \\
\hline \multirow{5}{*}{$\begin{array}{l}\text { Management } \\
\text { of the system }\end{array}$} & $\begin{array}{l}\text { (MS1) Maximum number of microgrids, to avoid supervising too much } \\
\text { microgrids in a same community. }\end{array}$ \\
\cline { 2 - 3 } & $\begin{array}{l}\text { (MS2) Minimum number of users per microgrid, to optimize management } \\
\text { efforts avoiding wasting them on too small microgrids. }\end{array}$ \\
\cline { 2 - 3 } & $\begin{array}{l}\text { (MS3) Maximum number of individual users, to extend as maximum as } \\
\text { possible microgrids benefits (in front of individual systems). }\end{array}$ \\
\cline { 2 - 3 } Adequacy of & $\begin{array}{l}\text { (MS4) Meters only installed at microgrid points, to save costs, in front of the } \\
\text { natural option of installing them at all the consumption points. }\end{array}$ \\
\hline \multirow{3}{*}{ equipment } & $\begin{array}{l}\text { (AE1) Minimum energy percentage generated by PV panels at each } \\
\text { generation point, ensuring each point is supplied by a certain amount of solar } \\
\text { resource (less variable than the wind resource). }\end{array}$ \\
\cline { 2 - 3 } & $\begin{array}{l}\text { (AE2) Minimum number of generation equipment at each generation point, so } \\
\text { that if an equipment fails at least another one still supply the electricity. }\end{array}$ \\
\cline { 2 - 3 } & $\begin{array}{l}\text { (AE3) Additional energy percentage at individual users, to compensate their } \\
\text { disadvantages (as less development opportunities) in front of microgrid users. }\end{array}$ \\
\hline
\end{tabular}




\section{Methodology for the design of stand-alone electrification systems}

The developed design methodology starts when a community is chosen to be electrified and guides the user (from now on "decider") through the design process until obtaining the solution to implement. A novel three-stage structure is proposed (Fig. 2). Stage 1 consists of three assessments to define the target community (Section 3.1). Stage 2 is the design process itself and groups the alternatives generation and selection phases identified in literature (Section 1). This Stage is divided in three decision levels, each one composed by an alternatives generation step followed by an alternatives selection step (Section 3.2). Stage 3, which is optional, allows trying to diminish the cost of the solution, maintaining the technical and social design considerations decided in the previous Stage (Section 3.3).

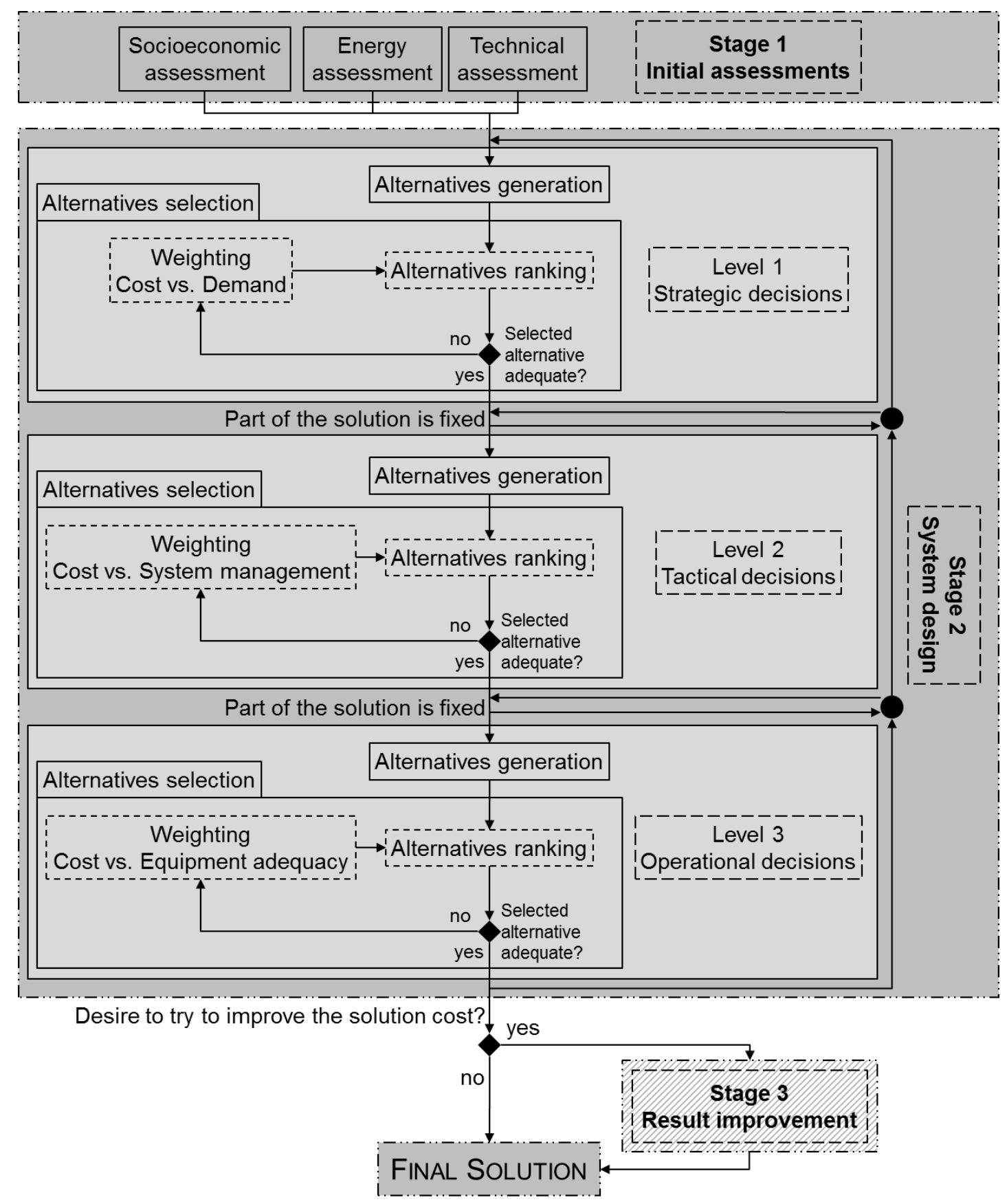

Fig. 2 - Structure of the methodology to design stand-alone electrification systems 


\subsection{Stage 1. Initial assessments}

Stage 1 "Initial assessments" consists of three evaluations to determine the characteristic data of the target community, which is then necessary for the design process. In the socioeconomic assessment, the emplacement of the consumption points, the energy, power and autonomy demands, and the social characteristics of population that could influence the management of the system (as conflicts between neighbors) are determined. In the energy assessment, the wind and solar resources at the area are studied. Usually the solar resource is considered uniform inside a community [36], and is established from databases that collect meteorological data from stations worldwide. The wind resource is much more variable and a detailed analysis is required [37]. For this purpose, an anemometer is placed at a point of the community to measure the wind speed and direction. With this data, the orography map and the power curves of the wind turbines, specialized software allows calculating the energy produced by each type of turbine at each point [38]. Finally, in the technical assessment, the technical characteristics and the cost of the equipment available in the region are gathered.

\subsection{Stage 2. System design}

Stage 2 "System design" is the design process itself. In literature two main phases were identified for the projects' design: the alternatives generation and selection. However, due to the great amount of design considerations proposed (Table 1), if all the alternatives were simultaneously generated the analysis would be too complex and especially confusing, because of the amount of solutions compared and the mix of significant and small differences between them. For example, if 10 demand scenarios, 10 distribution configurations and 10 typologies of equipment were studied (which are realistic values), 1000 alternatives would be generated combining all scenarios among them. Analyzing 1000 solutions together to select the most appropriate is impracticable, even more if considering several criteria, and would require from complex multicriteria tools and, specially, would never allow including the decider preferences easily.

For that reason, the whole process is divided in three decision levels, ordered according to the importance of the decisions taken. At each level there is an "Alternatives generation" (Step 1) where a set of electrification options is generated using a mathematical model (MILP) described in Section 4. Then, there is an "Alternatives selection" (Step 2) where the most appropriate option is selected through a multicriteria procedure based on the compromise programming described in Section 5. Moreover, the alternative selected at a level is used as starting point for the next one. This framework allows the decider to study in detail a specific characteristic of solutions before studying less significant aspects (Fig. 2). At each level, an easy-to-handle amount of alternatives is generated and the decider can deeply analyze solutions, so that his/her preferences can be taken into account. The general scheme of Stage 2 is as follows:

- At Level 1, the influence on the Cost of modifications on the Demand is studied (i.e. the covered electric uses are analyzed). For this purpose, several electrification alternatives are generated minimizing the cost for a set of different demand scenarios. These modifications have a high and long-term influence on solutions and their variation would imply the project redesign. In terms of project design, at Level 1, the groups of users proposed to form the microgrids are established. 
- At Level 2, the influence on the Cost of modifications on the Management of the system is studied (i.e. the amount, size and reach of microgrids as well as meters installation are analyzed). Thus, several electrification alternatives are generated minimizing the cost for a set of different configurations of the distribution scheme. These modifications have a moderate and medium-term influence on solutions, and their variation is possible during the project lifetime but with significant economic, technic and social investments. In terms of project design, starting from the solution of Level 1, some changes can be observed such as the extension of a connection between two microgrids forming a single microgrid, the addition of individual users to existing microgrids or even the creation of new microgrids.

- At Level 3, the influence on the Cost of modifications on the Adequacy of equipment is studied (i.e. the typology of equipment is analyzed in front of the lack of energy resources, equipment breakdowns or different development opportunities). Thus, several electrification alternatives are generated minimizing the cost for a set of different typologies, size and amount, of equipment. These modifications have a low and short-term influence on solutions, and their variation is possible during the project lifetime with slight economic, technic and social investments. In terms of project design, starting from the solution of Level 2, some changes can be observed such as the installation of an additional PV panel on a wind generation point or the substitution of wind turbines by equally powered PV panels.

Table 2 summarizes the three decision level structure of Stage 2 and is organized in three main columns related to the criteria, the subcriteria and the attributes. As observed, the Cost is studied at the three decision levels since it is usually the most important limitation in rural areas of developing countries [39]. At each level two criteria are compared: the Cost and a supporting criterion, the Demand (Level 1), the Management of the system (Level 2) and the Adequacy of equipment (Level 3). Each supporting criterion includes 3 or 4 subcriteria, each one in turn related to an attribute that defines the studied characteristic of solutions. The studied values of the attributes (whose combination allows generating the electrification alternatives) are from now on called "admissible values of the attributes". For example, in the criterion "Demand", there is the subcriterion "Energy" related to the attribute "Required energy by each point". Thus, the decider can propose different admissible values, i.e. different required energies for each point, which will lead to different electrification alternatives.

In detail, the design process from Stage 2 is as follows (Fig. 2). At Level 1 the decider establishes the basic Energy, Power and Autonomy admissible values (determined through the Initial assessments) and some progressive percentage increases. For each combination of admissible values, the cheapest solution meeting the specified Energy, Power and Autonomy demands is generated, using the mathematical model presented in Section 4. In this way, the set of electrification alternatives from Level 1 is obtained. To select the most appropriate one, the multicriteria procedure explained in Section 5 is used. Then, the top-ranked alternative is selected by the decider and used as starting point for Level 2. At Levels 2 and 3 the design process is similar. At each one the decider purposes one or more admissible values for the corresponding attributes and, through their combination, a set of minimum cost alternatives is generated. Then, the most appropriate one is selected by the decider. The alternative obtained at the end of Level 3 is the final solution for Stage 2. 
Table 2 - Criteria, subcriteria and attributes for each decision level

\begin{tabular}{|c|c|c|c|c|c|c|}
\hline & \multicolumn{2}{|c|}{ Criteria } & \multicolumn{2}{|c|}{ Subcriteria } & \multicolumn{2}{|c|}{ Attribute } \\
\hline \multirow{4}{*}{ Level 1} & $\mathbf{C F}_{1}$ & Cost & - & - & - & - \\
\hline & & & $\mathrm{CF}_{2-1}$ & Energy & $\mathbf{A F}_{2}$ & Required energy by each point \\
\hline & $\mathrm{CF}_{2}$ & Demand & $\mathrm{CF}_{2-2}$ & Power & $\mathbf{A F}_{3}$ & Required power by each point \\
\hline & & & $\mathrm{CF}_{2-3}$ & Autonomy & $\mathbf{A F}_{4}$ & Required autonomy \\
\hline \multirow{5}{*}{ Level 2} & $\mathbf{C S}_{1}$ & Cost & - & - & - & - \\
\hline & \multirow{4}{*}{$\mathbf{C S}_{2}$} & \multirow{4}{*}{$\begin{array}{l}\text { Management } \\
\text { of the system }\end{array}$} & $\mathrm{CS}_{2-1}$ & Amount of microgrids & $\mathbf{A S}_{2}$ & Maximum number of microgrids \\
\hline & & & $\mathrm{CS}_{2-2}$ & Size of microgrids & $\mathbf{A S}_{\mathbf{3}}$ & Minimum number of users per microgrid \\
\hline & & & $\mathrm{CS}_{2-3}$ & Reach of microgrids & $\mathbf{A S}_{4}$ & Maximum number of individual users \\
\hline & & & $\mathrm{CS}_{2-4}$ & Meters installation & $\mathbf{A S}_{\mathbf{5}}$ & Meters at all the points or in microgrids \\
\hline \multirow{4}{*}{ Level 3} & $\mathrm{CT}_{1}$ & Cost & - & - & - & - \\
\hline & \multirow{3}{*}{$\mathrm{CT}_{2}$} & \multirow{3}{*}{$\begin{array}{l}\text { Adequacy of } \\
\text { equipment }\end{array}$} & $\mathbf{C T}_{2-1}$ & $\begin{array}{l}\text { PV generation } \\
\text { percentage }\end{array}$ & $\mathbf{A T}_{\mathbf{2}}$ & $\begin{array}{l}\text { Minimum energy percentage generated by } \\
\text { PV panels at each generation point }\end{array}$ \\
\hline & & & $\mathrm{CT}_{2-2}$ & $\begin{array}{l}\text { Amount of generation } \\
\text { equipment }\end{array}$ & $\mathbf{A T}_{\mathbf{3}} \mid$ & $\begin{array}{l}\text { Minimum number of generation equipment } \\
\text { at each generation point }\end{array}$ \\
\hline & & & $\mathrm{CT}_{2-3}$ & $\begin{array}{l}\text { Individual users } \\
\text { energy }\end{array}$ & $\mathbf{A T}_{\mathbf{4}}$ & $\begin{array}{l}\text { Additional energy percentage at individual } \\
\text { users in front of microgrid users }\end{array}$ \\
\hline
\end{tabular}

Finally, between one level and the next one, part of the solution is automatically fixed to avoid that previous decisions (more important) be influenced by later decisions (less significant). When an alternative is selected at a level, the decider proposes admissible values for the attributes of the next level; with this information, part of the solution is automatically fixed, although the decider can then adapt the fixed elements to his/her preferences. From Level 1 to Level 2 the microgrids with an enough size (higher than or equal to the maximum admissible value of attribute $\mathrm{AS}_{3}$ studied at Level 2) are fixed. From Level 2 to Level 3, the existing wires and their direction are automatically fixed.

Additionally, Stage 2 is complemented by two iterative procedures that allow the decider to adjust the decisions taken when going in-depth into the problem. The first one comprehends the three decision levels to study many design options by going from the end of a level to the beginning of the same or a previous one. The second procedure focus on the alternatives selection step of each level to modify the relative importance (that is, the weights) assigned to the criteria and subcriteria. This procedure is explained in detail in Section 5.

\subsection{Stage 3. Result improvement}

Stage 3 "Result improvement", which is optional, aims to try to improve the cost of the solution selected in Stage 2, maintaining the decided considerations. This Stage arises from the fact that part of the solution is fixed between decision levels in Stage 2, what can lead to unnecessary cost increases, depending on the decisions taken. In Stage 3 the mathematical model is solved again in order to try to obtain a cheaper global solution that still meets all the decided design considerations from Stage 2.

\section{Alternatives generation}

As introduced in Section 3, each decision level from Stage 2 is composed by two main steps: alternatives generation (Step 1) and alternatives selection (Step 2). This Section focuses on Step 1, consisting of generating and optimizing a set of alternatives, studying a specific characteristic of solutions at each level. 
Currently, the use of mathematical models to solve real problems is increasing thanks to the last advances in computation technologies [40]. Ferrer-Martí et al. [33] developed a MILP model to design stand-alone wind-PV systems for rural communities, minimizing the cost, and considering the detail of the energy, power and autonomy demands, the energy resources and the distribution through microgrids and individual systems (MILP1). Domenech et al. [35] modified the previous model adding two sets of socials considerations (see Table 1): to ease the management of the system studying the electric distribution scheme (MILP2) and, moreover, to improve the adequacy of equipment to end-users studying their typology (MILP3). These three models are respectively used for the alternatives generation step of the three decision levels. The basic structure of the three models is the same but new constraints are added at each level according to the studied considerations. Next, the MILP1 and the constraints added for the MILP2 and the MILP3 are briefly summarized:

- Parameters. Data of the problem necessary to solve the model.

- Generation and accumulation. Wind turbines (types, cost, energy generated and maximum number at one generation point), PV panels (types, cost, maximum power, energy generated and maximum number at one generation point) and batteries (types, cost, capacity, efficiency and discharge factor).

- Network definition. Distance between points, wires (types, cost per meter, resistance, maximum intensity and efficiency), nominal, minimum and maximum voltage, and maximum length of a wire segment of the microgrid.

- Equipment. Solar controllers (types, cost and maximum power), inverters (types, cost, maximum power, efficiency and maximum at a point) and meters (cost).

$\circ$ Demand (Level 1). Required energy $\left(\mathrm{AF}_{2}\right)$ and power $\left(\mathrm{AF}_{3}\right)$ by each point and required autonomy $\left(\mathrm{AF}_{4}\right)$.

- Management of the system (Level 2). Maximum number of microgrids $\left(\mathrm{AS}_{2}\right)$, minimum number of users per microgrid $\left(\mathrm{AS}_{3}\right)$, maximum number of individual users $\left(\mathrm{AS}_{4}\right)$ and meters at all the points or just in microgrids $\left(\mathrm{AS}_{5}\right)$.

- Adequacy of equipment (Level 3). Minimum energy percentage generated by $\mathrm{PV}$ panels at each generation point $\left(\mathrm{AT}_{2}\right)$, minimum number of generation equipment at each generation point $\left(\mathrm{AT}_{3}\right)$ and additional energy percentage at individual users in front of microgrid users $\left(\mathrm{AT}_{4}\right)$.

- Variables. Elements that define the solution and whose value is initially unknown.

$\circ$ Equipment. Integer variables indicating the number of each type of equipment to be installed at each point.

○ Definition of the network. Binary variables indicating if two points are joined by a type of wire, and real variables for the energy and power flows between points.

- Objective function. In this case, to minimize the cost of the initial investment including all the equipment.

- Constraints. Requirements of the problem delimiting the solution.

$\circ$ Generation and accumulation. At each point, an energy and power balance is realized. Batteries must be installed in generation points and its capacity must cover the days of autonomy considering the demand and the discharge factor.

$\circ$ Definition of the network. Relationship between energy and power flows and the existence of a wire is established. The installed wire must satisfy maximum voltage drop and maximum intensity. Microgrid structure must be radial. 
- Equipment. Solar controllers must be adequately powered for PV panels. Due to technical constraints, an adequate wind controller is included in each wind turbine. Inverters must satisfy the power demand. Controllers and inverters must be installed in generation points.

○ System management (only for MILP2 and MILP3). The amount of microgrids is limited $\left(\mathrm{AS}_{2}\right)$. The number of users of each microgrid is lower bounded $\left(\mathrm{AS}_{3}\right)$. The amount of individual users is limited $\left(\mathrm{AS}_{4}\right)$. Meters are installed at all the points or just in microgrid points $\left(\mathrm{AS}_{5}\right)$.

- Adequacy of equipment (only for MILP3). At each point, an energy balance is realized just for $\mathrm{PV}$ generation $\left(\mathrm{AT}_{2}\right)$. Each point is supplied by, at least, a certain amount of generation equipment $\left(\mathrm{AT}_{3}\right)$. An additional energy percentage is supplied to individual users $\left(\mathrm{AT}_{4}\right)$.

To generate the alternatives at each decision level, the decider proposes several values (admissible values) of the studied attributes. For each combination of admissible values, the corresponding model (MILP1, MILP2 or MILP3) is solved, finding the minimum cost solution. However, the calculation time needed to solve the mathematical models is still a challenge. For that reason, a heuristic procedure based on the MILPs relaxation is proposed to ensure that a feasible and near-to-optimal solution is found in a short calculation time. As detailed in Appendix A, at each level the heuristic procedure consists of, first, solving a reduced version of the MILP model and, then, trying to improve the solution cost solving the usual MILP model. The reduced version of the models is obtained by reducing the problem dimension; that is limiting the number of possible connections of the microgrids: a point can be connected to another point only if its individual electrification cost is higher than the connection cost (wire extension).

Complementarily, Appendix B shows two computational experiments that have been carried out to validate the heuristic resolution process. On the one hand, results demonstrate that the heuristic procedure always finds a feasible solution (what does not always happen without using it) and that the average difference in the solution cost obtained when solving with and without the heuristic is very small, less than $1 \%$. On the other hand, results prove that the average difference in the solution cost obtained using the proposed three-decision-level structure and without using it (and so solving all the alternatives simultaneously, as usually done in literature) are also negligible, also less than $1 \%$. Additionally, as explained previously, the proposed decision level framework allows the decider to interact along the process and to adjust the decisions taken when going in-depth into the problem.

\section{Alternatives selection}

This Section focuses on the alternatives selection process (Step 2), which consists of a multicriteria selection of the most appropriate alternative among the generated set, at each decision level.

As stated in Section 1, this process is generally organized in four points [28]. First, some evaluation criteria are defined (Section 5.1) according to the studied context or region $[41,42,43]$. Second, the criteria are weighted (Section 5.2), i.e. a value is assigned to each one representing its importance regarding the others. For this purpose the Analytic Hierarchy Process (AHP) is very used since it allows reducing 
inconsistencies in the decision-making [29,44]. Third, each alternative is evaluated according to each criterion (Section 5.3), and a quality index is calculated for each alternative. To calculate this index, several aid tools are proposed, particularly for energy planning problems [30, 31]. Among others, the compromise programming (used in this research) is based on comparing each alternative to an ideal solution [45, 46, 47]. Finally, fourth, results are aggregated for their analysis (Section 5.4). This point appears since the same multicriteria technique applied by several decision-makers or different techniques applied by a single decision-maker, can lead to different results [48]. Therefore results should be converged, although this point has not been very used in literature [28].

\subsection{Criteria definition}

To define a set of evaluation criteria for the design methodology, several meetings were realized with technical and social rural electrification experts from the NGOs Practical Action, Peru (PA), Engineering Without Borders, Spain (ESF) and Green Empowerment, USA (GE). The aim was to identify the criteria that rural electrification promoters (deciders) tend to use when designing real electrification projects and, particularly, what turns a solution more or less adequate to a specific context or region and its population. Therefore, the chosen criteria must include the point of view of all the stakeholders involved in the project: the promoter, the local and regional authorities, the end-users, etc. In this way, 28 evaluation criteria were initially listed; a too high amount that can lead to complex and confusing decisions [49]. Consequently the list size was reduced grouping in 4 generic criteria with their corresponding subcriteria, which are presented in the two first main columns of Table 2. In this way, the decider can focus, at each level, on a reduced set of considerations.

\subsection{Weighting criteria}

Once the criteria and subcriteria are defined, they are weighted: a value is assigned to each one representing its importance regarding the others. At the end of Section 3.2 an interactive procedure was presented allowing the decider to adjust the weights, but the first iteration can be still an issue. In exchange, if some starting weights are automatically proposed, an alternatives starting ranking can be obtained and then the decider can analyze it to modify the weights (and so the ranking) according to his/her preferences, if necessary.

To define the value of the starting weights, several political, economic, social and technical electrification experts from the NGOs PA and ESF were surveyed [5]. The aim was to determine some weights that would be appropriate for rural areas, so the experts chosen had a wide experience in electrification projects of many contexts (particularly the coast, highlands and jungle of the Andean region). Table 3 shows the obtained starting weights. As observed, there are weights for the criteria and the subcriteria. Therefore, the global weights of the subcriteria are calculated multiplying their own weights and the weight of the corresponding criteria. For example, the weight of the subcriterion Energy would be $0.40 * 0.52$. 
Table 3 - Starting weights (SW) for the criteria and subcriteria of the three decision levels

\begin{tabular}{|c|c|c|c|c|c|c|}
\hline & Crite & eria & SW & Subcr & iteria & SW \\
\hline \multirow{4}{*}{ Level 1} & \multicolumn{2}{|c|}{\begin{tabular}{l|l}
$\mathbf{C F}_{1}$ & Cost
\end{tabular}} & 0.48 & \multicolumn{3}{|l|}{-} \\
\hline & \multirow{3}{*}{$\mathrm{CF}_{2}$} & \multirow{3}{*}{ Demand } & \multirow{3}{*}{0.52} & $\mathrm{CF}_{2-1}$ & Energy & 0.40 \\
\hline & & & & $\mathrm{CF}_{2-2}$ & Power & 0.32 \\
\hline & & & & $\mathrm{CF}_{2-3}$ & Autonomy & 0.28 \\
\hline \multirow{5}{*}{ Level 2} & $\mathbf{C S}_{\mathbf{1}}$ & Cost & 0.48 & - & & \\
\hline & \multirow{4}{*}{$\mathrm{CS}_{2}$} & \multirow{4}{*}{$\begin{array}{l}\text { Management } \\
\text { of the system }\end{array}$} & \multirow{4}{*}{0.52} & $\mathbf{C S}_{2-1}$ & Amount of microgrids & 0.20 \\
\hline & & & & $\mathrm{CS}_{2-2}$ & Size of microgrids & 0.30 \\
\hline & & & & $\mathrm{CS}_{2-3}$ & Reach of microgrids & 0.32 \\
\hline & & & & $\mathrm{CS}_{2-4}$ & Meters installation & 0.18 \\
\hline \multirow{4}{*}{ Level 3} & $\mathbf{C T}_{1}$ & Cost & 0.47 & - & & \\
\hline & \multirow{3}{*}{$\mathbf{C T}_{2}$} & \multirow{3}{*}{$\begin{array}{l}\text { Adequacy of } \\
\text { equipment }\end{array}$} & \multirow{3}{*}{0.53} & $\mathbf{C T}_{2-1}$ & PV generation percentage & 0.38 \\
\hline & & & & $\mathrm{CT}_{2-2}$ & Amount of generation equipment & 0.30 \\
\hline & & & & $\mathrm{CT}_{2-3}$ & Individual users energy & 0.32 \\
\hline
\end{tabular}

2

\subsection{Alternatives evaluation}

Once the criteria and subcriteria are weighted, each alternative is evaluated according to each criterion and subcriterion, with the corresponding attribute. In the third main column of Table 2 the attributes were defined, whose value is the admissible value that an alternative can attain for an attribute. Now the real values obtained for each alternative are compared with the admissible values to evaluate the accomplishment of each alternative with each attribute (Table 4). Note that real values are associated to +/symbols that indicate whether a higher/lower real value implies a better alternative rank.

Table 4 - Attributes and real values of the attributes for the three decision levels

\begin{tabular}{|c|c|c|c|c|c|}
\hline & \multicolumn{2}{|c|}{ Attribute } & \multicolumn{3}{|c|}{ Real value of the attribute } \\
\hline \multirow{4}{*}{ Level 1} & - & & $\mathrm{RF}_{1}$ & - & Cost of the solution \\
\hline & $\mathrm{AF}_{2}$ & Required energy by each point & $\mathrm{RF}_{2}$ & + & $\begin{array}{l}\text { Point with the lower ratio between supplied } \\
\text { energy and minimum energy required }\end{array}$ \\
\hline & $\mathrm{AF}_{3}$ & Required power by each point & $\mathrm{RF}_{3}$ & + & $\begin{array}{l}\text { Point with the lower ratio between supplied } \\
\text { power and minimum power required }\end{array}$ \\
\hline & $\mathrm{AF}_{4}$ & Days of autonomy required & $\mathrm{RF}_{4}$ & + & $\begin{array}{l}\text { Point with the lower ratio between available } \\
\text { autonomy and minimum autonomy required }\end{array}$ \\
\hline \multirow{5}{*}{ Level 2} & - & & $\mathrm{RS}_{1}$ & - & Cost of the solution \\
\hline & $\mathrm{AS}_{2}$ & Maximum number of microgrids & $\mathrm{RS}_{2}$ & - & Number of microgrids \\
\hline & $\mathrm{AS}_{3}$ & Minimum number of users per microgrid & $\mathrm{RS}_{3}$ & + & Number of users of the smaller microgrid \\
\hline & $\mathrm{AS}_{4}$ & Maximum number of individual users & $\mathrm{RS}_{4}$ & - & Number of individual users \\
\hline & $\mathrm{AS}_{5}$ & Meters at all the points or in microgrids & $\mathrm{RS}_{5}$ & + & Amount of meters installed \\
\hline \multirow{4}{*}{ Level 3} & - & & $\mathrm{RT}_{1}$ & - & Cost of solution \\
\hline & $\mathrm{AT}_{2}$ & $\begin{array}{l}\text { Minimum energy percentage generated by } \\
\text { PV panels at each generation point }\end{array}$ & $\mathrm{RT}_{2}$ & + & $\begin{array}{l}\text { Generation point with lower ratio between energy } \\
\text { produced by PV panels and total energy produced }\end{array}$ \\
\hline & $\mathrm{AT}_{3}$ & $\begin{array}{l}\text { Minimum number of generation equipment } \\
\text { at each generation point }\end{array}$ & $\mathrm{RT}_{3}$ & + & $\begin{array}{l}\text { Generation point with the lower amount of } \\
\text { generation equipment installed }\end{array}$ \\
\hline & $\mathrm{AT}_{4}$ & $\begin{array}{l}\text { Additional energy percentage at individual } \\
\text { users in front of microgrid users }\end{array}$ & $\mathrm{RT}_{4}$ & + & $\begin{array}{l}\text { Individual point with the lower ratio between } \\
\text { supplied energy and required energy in microgrid }\end{array}$ \\
\hline
\end{tabular}

15 Once the real values of the attributes are obtained, the alternatives can be evaluated and

16 ranked. For this purpose multicriteria decision-aid tools are very useful to strength the

17 decision process [28]. In particular, this research is applied to rural areas, being

18 necessary easy and transparent tools that allow clearly showing results to all the

19 stakeholders involved in the project. The compromise programming [45, 46, 47] meets

20 all of these conditions. This method is based on the principle that, if a decision-maker 
acts rationally, the best alternative will be the closer one to an ideal solution, which is a utopian solution attaining the optimum value for all the criteria [45, 46, 47]. The closeness concept is understood as the mathematical distance (eq. 1).

$L_{p}(x)=\left[\sum_{i=1}^{n}\left(W_{i}\right)^{p} \cdot\left(\frac{F_{i}^{*}-f_{i}(x)}{F_{i}^{*}-f_{i}^{*}}\right)^{p}\right]^{1 / p}$

where $p$ is the metric, whose significance is discussed in Section $5.4 ; L_{p}(x)$ is the distance between an alternative and the ideal solution depending on the metric $p ; W_{i}$ is the weight of the criterion $i ; f_{i}(x)$ is the value of the alternative for criterion or subcriterion $i$ (measured through the real value of the attributes); $F_{i}{ }^{*}$ is the ideal value for criterion $i$ (the best value obtained among all the generated alternatives), $f_{i}^{*}$ is the anti-ideal value for criterion $i$ (the worst value obtained among all the generated alternatives); and $n$ is the amount of criteria. Therefore, to rank the alternatives at each decision level, the $L_{p}(x)$ distance is calculated for each alternative and used as a quality index: the lower is the $L_{p}(x)$ value, the higher is the alternative position in the ranking.

\subsection{Final ranking}

As expected, depending on the metric $p$ used, the obtained rank can be different. Therefore an appropriate $p$ value must be chosen existing no rationale among one or another value [50]. The metric $p$ represents the importance ascribed to the deviation from the ideal value for a criterion; in other words, the frustration against each criterion. The higher is the $p$ value, the more importance is assigned to the maximum deviation [50]. In particular, $L_{1}(x)$ considers an importance to criteria's deviation proportional to their weights, while $L_{\infty}(x)$ only considers the maximum deviation criterion. In this problem, the aim is to find a single ranking for each decision level, which does not require from the decider to choose the $p$ value. In this sense, Diaz-Balteiro \& Romero [51] propose a linear combination of metrics 1 and $\infty: L_{F}(x)=\alpha \cdot L_{1}(x)+[1-\alpha] \cdot L_{\infty}(x)$. Specifically, $\alpha=0.5$ is chosen as proposed by San Cristóbal [52] for a renewable energy project.

\section{Illustration of the design methodology}

To illustrate the functioning of the proposed design methodology, one of the authors (from now on the decider) designs the electrification system of a community. On the one hand, the decider has a great experience on the design of rural electrification projects in different contexts from the Andean region (especially Peru, Bolivia and Ecuador) and is an active member of the promoter NGOs in charge of such projects. Moreover the decider has participated during the development of the design methodology and knows how the tool works. On the other hand, the studied community is part of a real community from the Andean highlands. The whole community is not studied, since the aim of this Section is to briefly and clearly show the design process followed by a decider. Therefore, working on a reduced community, the way as solutions are adapted to decider's preferences can be easily understood. Through this Section, the possibilities offered by the methodology to study many design options aiming to obtain the most appropriate electrification system for a community are shown. 


\section{Stage 1. Initial assessments}

To identify the characteristic data of the target community and the population, the socioeconomic, energy and technical assessments are carried out. In this way, the next data are gathered:

- Socioeconomic assessment.

- There are 7 consumption points: a communal center (1) and six houses (2 to 7).

- The point 7 is discarded since the owner does not want the electric service.

- Fig. 3 shows the emplacement of the points to be electrified (1 to 6).

○ Communal center demand. Energy: 600Wh/day; power: 500W.

○ Houses demand. Energy: 300Wh/day; power: 200W.

○ There are no conflicts between neighbors, so microgrids are viable.

- Energy assessment:

○ Autonomy demand: 2 days, considering resources (wind and sun) variability.

- The solar irradiation of the worst month of the year is gathered [53].

$\circ$ The wind speed and direction are measured and the least resource month is identified using specialized software [38], see Fig. 3.

- Technical assessment. The next equipment are used:

○ Wind turbines (4 types). Energy: 259 to $18007 \mathrm{Wh} /$ day. Cost: $\$ 1139$ to $\$ 5645$. Maximum number that can be installed at a same point: 3 .

- Wind controllers. An adequate wind controller is still included in each turbine.

o PV panels (4 types). Energy: 217 to $652 \mathrm{Wh} /$ day. Max power: 50 to $150 \mathrm{~W}$. Cost: $\$ 451$ to $\$ 1000$. Maximum number that can be installed at a same point: 30 .

○ PV controllers (4 types). Maximum power: 50 to $200 \mathrm{~W}$. Cost: $\$ 67$ to $\$ 125$.

○ Batteries (4 types). Capacity: 1500 to 3000 Wh. Cost: $\$ 225$ to \$325. Efficiency: 0.85 Discharge factor: 0.60 .

○ Inverters (4 types). Maximum power: 300 to $3000 \mathrm{~W}$. Cost: $\$ 377$ to $\$ 2300$. Efficiency $85 \%$. Maximum number that can be installed at a same point: 30 .

○ Meters (1 type). Cost: $\$ 50$.

○ Wires (3 types). Resistance: 2.6 to $0.16 \Omega / \mathrm{km}$. Maximum intensity: 64 to $380 \mathrm{~A}$. Cost: $\$ 4.94$ to $\$ 5.79 / \mathrm{m}$. Efficiency: 0.91. Maximum segment length: $1000 \mathrm{~m}$. Nominal voltage: $220 \mathrm{~V}$. Minimum voltage: $210 \mathrm{~V}$. Maximum voltage: $230 \mathrm{~V}$.

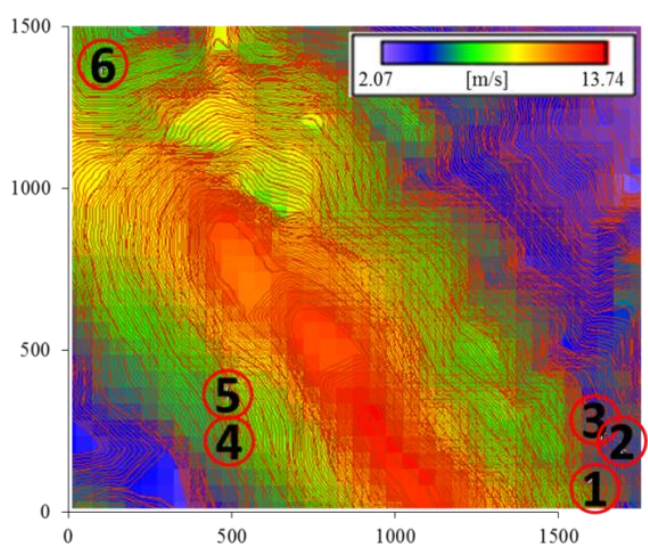

Fig. 3 - Wind map of the region and coordinates of the consumption points to electrify 


\section{Stage 2. System design. Level 1. Strategic decisions. Cost vs Demand}

The decider proposes the next Demand scenarios:

- Required energy $\left(\mathrm{AF}_{2}\right)$ and power $\left(\mathrm{AF}_{3}\right)$ by each point. 3 scenarios: basic (defined in the socioeconomic assessment); medium (+25\%); and high $(+50 \%)$.

- Days of autonomy required $\left(\mathrm{AF}_{4}\right) .1$ scenario: 2 days (see energy assessment).

With these data, 3 electrification alternatives are obtained using the alternatives generation process presented in Section 4. Table 5 shows their admissible and real values of the attributes. With the real values and the starting weights of the criteria and subcriteria (Table 6, iteration 0 ) an $L_{F}(x)$ starting value is automatically calculated for each alternative (Table 5, $L_{F}(x)$ of iteration 0 ), in the way described in Section 5 . As observed, the most compromised alternative is A1 (lowest $L_{F}(x)$ value), followed by A2 and then A3. However, the decider goes into the iterative procedure by modifying the weights of the criteria and subcriteria to adjust them to his preferences (Table 6, iteration 1), and a new $L_{F}(x)$ value is obtained for each alternative (Table 5, $L_{F}(x)$ of iteration 1). In this case, the best ranked alternative is $\mathrm{A} 2$, followed by $\mathrm{A} 1$ and $\mathrm{A} 3$. The decider selects the best classified alternative (A2) for the next level. Fig. 4 shows its electric distribution scheme, where green circles represent generation points while yellow squares are points supplied by a microgrid.

Table 5 - Admissible and real values of the attributes, and $L_{F}(x)$ value for the alternatives of Stage 2, Level 1

\begin{tabular}{|l|l|l|l|l|}
\hline \multicolumn{2}{|l|}{ Attributes } & $\mathbf{A 1}$ & $\mathbf{A 2}$ & $\mathbf{A 3}$ \\
\hline \multirow{3}{*}{$\begin{array}{l}\text { Admissible } \\
\text { values }\end{array}$} & $\mathbf{A F}_{\mathbf{2}}$ & $0 \%(600 ; 300 \mathrm{Wh} /$ day $)$ & $25 \%$ & $50 \%$ \\
\cline { 2 - 5 } & $\mathbf{A F}_{\mathbf{3}}$ & $0 \%(500 ; 200 \mathrm{~W})$ & $25 \%$ & $50 \%$ \\
\cline { 2 - 6 } & $\mathbf{A F}_{\mathbf{4}}$ & $0 \%(2$ days) & $0 \%$ & $0 \%$ \\
\hline \multirow{4}{*}{$\begin{array}{l}\text { Real } \\
\text { values }\end{array}$} & $\mathbf{R F}_{\mathbf{1}}$ & 10108 & 12033 & 12350 \\
\cline { 2 - 6 } & $\mathbf{R F}_{\mathbf{2}}$ & $0 \%$ & $26 \%$ & $57 \%$ \\
\cline { 2 - 6 } & $\mathbf{R F}_{\mathbf{3}}$ & $20 \%$ & $43 \%$ & $50 \%$ \\
\cline { 2 - 5 } & $\mathbf{R F}_{\mathbf{4}}$ & $8 \%$ & $4 \%$ & $3 \%$ \\
\hline
\end{tabular}

Table 6 - Weights of the criteria and subcriteria used at Stage 2, Level 1

\begin{tabular}{|c|c|c|c|c|c|}
\hline \multirow{2}{*}{ Criteria } & \multicolumn{2}{|l|}{ Weight } & \multirow{2}{*}{ Subcriteria } & \multicolumn{2}{|l|}{ Weight } \\
\hline & Iteration 0 & Iteration 1 & & Iteration 0 & Iteration 1 \\
\hline $\mathrm{CF}_{1}$ & 0.48 & 0.50 & - & & \\
\hline \multirow{3}{*}{$\mathrm{CF}_{2}$} & \multirow{3}{*}{0.52} & \multirow{3}{*}{0.50} & $\mathrm{CF}_{2-1}$ & 0.40 & 0.10 \\
\hline & & & $\mathrm{CF}_{2-2}$ & 0.32 & 0.90 \\
\hline & & & $\mathrm{CF}_{2-3}$ & 0.28 & 0.00 \\
\hline
\end{tabular}

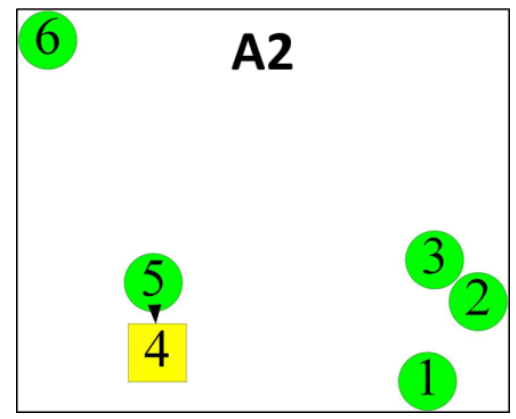

Fig. 4 - Distribution scheme of the alternative selected at Stage 2, Level 1 


\section{Stage 2. System design. Level 2. Tactical decisions. Cost vs Management of the system}

The decider proposes the next scenarios for the Management of the system:

- Maximum number of microgrids $\left(\mathrm{AS}_{2}\right) .2$ scenarios: 1 and 2.

- Minimum number of users per microgrid $\left(\mathrm{AS}_{3}\right) .2$ scenarios: 2 and 3.

- Maximum number of individual users $\left(\mathrm{AS}_{4}\right) .1$ scenario: 6.

- Meters at all the points or in microgrids $\left(\mathrm{AS}_{5}\right) .2$ scenarios: all and microgrid points.

Additionally, from Level 1 to Level 2, part of the solution is automatically fixed: the microgrids with a higher or equal size than the maximum admissible value for the attribute $\mathrm{AS}_{3}$ (3 users per microgrid). However, the single microgrid formed in alternative A2 has 2 users so no elements would be automatically fixed, although the decider prefers to maintain the aforesaid microgrid of 2 users.

With these data, 8 electrification alternatives are obtained. Table 7 shows their admissible and real values of the attributes. With the real values and the starting weights of the criteria and subcriteria (Table 8 ) an $L_{F}(x)$ starting value is automatically calculated for each alternative (Table 7). Additionally, the distribution scheme of the alternatives is shown in Fig. 5. As observed, only two different configurations are obtained, so the decider temporarily selects the best ranked alternative for each scheme (B1 and B3) and goes into the iterative procedure to propose new scenarios for the Management of the system. Note that the design methodology allows the decider to select more than one alternative along the decision process, to study them in parallel in the next levels.

Table 7 - Admissible and real values of the attributes, and $L_{F}(x)$ value for the alternatives of Stage 2, Level 2

\begin{tabular}{|c|c|c|c|c|c|c|c|c|c|}
\hline \multicolumn{2}{|l|}{ Attributes } & B1 & B2 & B3 & B4 & B5 & B6 & B7 & B8 \\
\hline \multirow{4}{*}{$\begin{array}{l}\text { Admissible } \\
\text { values }\end{array}$} & $\mathbf{A S}_{\mathbf{2}}$ & 1 & 1 & 1 & 1 & 2 & 2 & 2 & 2 \\
\hline & $\mathbf{A S}_{\mathbf{3}}$ & 2 & 2 & 3 & 3 & 2 & 2 & 3 & 3 \\
\hline & $\mathbf{A S}_{\mathbf{4}}$ & 6 & 6 & 6 & 6 & 6 & 6 & 6 & 6 \\
\hline & $\mathbf{A S}_{\mathbf{5}}$ & All & Mgrid & All & Mgrid & All & Mgrid & All & Mgrid \\
\hline \multirow{5}{*}{$\begin{array}{l}\text { Real } \\
\text { values }\end{array}$} & $\mathbf{R S}_{1}$ & 12033 & 11833 & 15518 & 15468 & 12033 & 11833 & 15518 & 15468 \\
\hline & $\mathbf{R S}_{\mathbf{2}}$ & 1 & 1 & 1 & 1 & 1 & 1 & 1 & 1 \\
\hline & $\mathbf{R S}_{3}$ & 2 & 2 & 5 & 5 & 2 & 2 & 5 & 5 \\
\hline & $\mathbf{R S}_{\mathbf{4}}$ & 4 & 4 & 1 & 1 & 4 & 4 & 1 & 1 \\
\hline & $\mathbf{R S}_{5}$ & 6 & 2 & 6 & 5 & 6 & 2 & 6 & 5 \\
\hline \multicolumn{2}{|c|}{$L_{F}(x)$ (iteration 0$)$} & 0.410 & 0.517 & 0.483 & 0.491 & 0.410 & 0.517 & 0.483 & 0.491 \\
\hline
\end{tabular}

Table 8 - Weights of the criteria and subcriteria used at Stage 2, Level 1

\begin{tabular}{|l|l|l|l|}
\hline \multirow{2}{*}{ Criteria } & Weight & \multirow{2}{*}{ Subcriteria } & Weight \\
\cline { 2 - 4 } & Iteration 0 & & Iteration 0 \\
\hline $\mathbf{C S}_{\mathbf{1}}$ & 0.48 & - & \\
\hline \multirow{4}{*}{$\mathbf{C S}_{2}$} & \multirow{3}{*}{0.52} & $\mathbf{C S}_{2-1}$ & 0.20 \\
\cline { 3 - 4 } & & $\mathbf{C S}_{2-1}$ & 0.30 \\
\cline { 3 - 4 } & & $\mathbf{C S}_{2-2}$ & 0.32 \\
\hline & $\mathbf{C S}_{2-3}$ & 0.18 \\
\hline
\end{tabular}




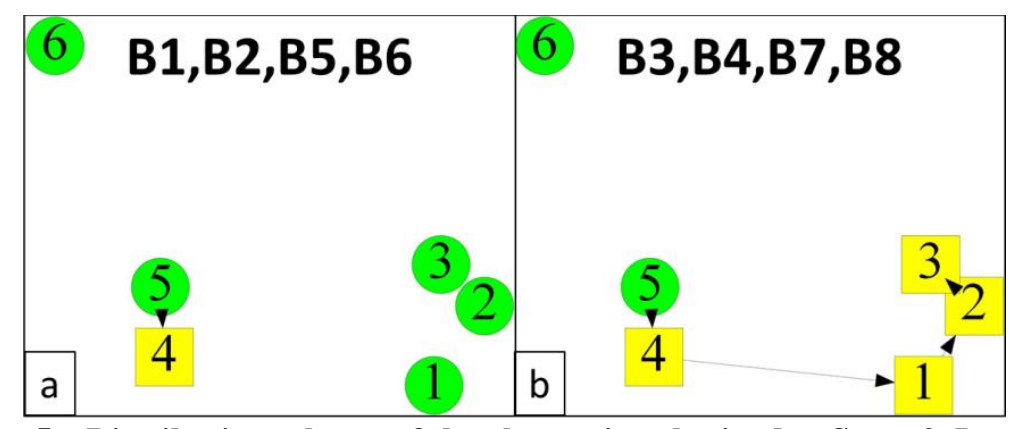

Fig. 5 - Distribution scheme of the alternative obtained at Stage 2, Level 2

The decider proposes the next new scenarios for the Management of the system:

- Maximum number of microgrids $\left(\mathrm{AS}_{2}\right) .2$ scenarios: 1 and 2.

- Minimum number of users per microgrid $\left(\mathrm{AS}_{3}\right) .2$ scenarios: 2 and 3.

- Maximum number of individual users $\left(\mathrm{AS}_{4}\right) .2$ scenarios: 6 and 0.

- Meters at all the points or in microgrids $\left(\mathrm{AS}_{5}\right) .1$ scenario: all points.

Additionally, in this case, the decider does not fix any element from the alternative A2.

With these data, 8 new electrification alternatives are obtained, which are compared to the 2 alternatives selected previously (B1 and B3). Table 9 shows their admissible and real values of the attributes. With the real values and the starting weights of the criteria and subcriteria (Table 8) an $L_{F}(x)$ starting value is automatically calculated for each alternative (Table 9). Additionally, the distribution scheme of all the alternatives is shown in Fig. 6. As observed, a greater range of configurations is obtained. Finally, the decider selects the two best ranked alternatives (B1 and B3) for the next level.

Table 9 - Admissible and real values of the attributes, and $L_{F}(x)$ value for the alternatives of Stage 2, Level 2 (bis)

\begin{tabular}{|c|c|c|c|c|c|c|c|c|c|c|c|}
\hline Attributes & & B1 & B3 & B9 & B10 & B11 & B12 & B13 & B14 & B15 & B16 \\
\hline \multirow{4}{*}{$\begin{array}{l}\text { Admissible } \\
\text { values }\end{array}$} & $\mathbf{A S}_{2}$ & 1 & 1 & 1 & 1 & 1 & 1 & 2 & 2 & 2 & 2 \\
\hline & $\mathbf{A S}_{\mathbf{3}}$ & 2 & 3 & 2 & 2 & 3 & 3 & 2 & 2 & 3 & 3 \\
\hline & $\mathbf{A S}_{\mathbf{4}}$ & 6 & 6 & 6 & 0 & 6 & 0 & 6 & 0 & 6 & 0 \\
\hline & $\mathbf{A S}_{\mathbf{5}}$ & All & All & All & All & All & All & All & All & All & All \\
\hline \multirow{5}{*}{$\begin{array}{l}\text { Real } \\
\text { values }\end{array}$} & $\mathbf{R S}_{1}$ & 12033 & 15518 & 12033 & 19722 & 12320 & 19722 & 12033 & 16454 & 12320 & 16454 \\
\hline & $\mathbf{R S}_{\mathbf{2}}$ & 1 & 1 & 1 & 1 & 0 & 1 & 1 & 2 & 0 & 2 \\
\hline & $\mathbf{R S}_{\mathbf{3}}$ & 2 & 5 & 2 & 6 & 0 & 6 & 2 & 3 & 0 & 3 \\
\hline & $\mathbf{R S}_{4}$ & 4 & 1 & 4 & 0 & 6 & 0 & 4 & 0 & 6 & 0 \\
\hline & $\mathbf{R S}_{5}$ & 6 & 6 & 6 & 6 & 6 & 6 & 6 & 6 & 6 & 6 \\
\hline
\end{tabular}

\begin{tabular}{|l|l|l|l|l|l|l|l|l|l|l|}
\hline $\boldsymbol{L}_{\boldsymbol{F}}(\boldsymbol{x})$ (iteration 0) & 0.324 & 0.283 & 0.324 & 0.514 & 0.400 & 0.514 & 0.324 & 0.388 & 0.400 & 0.388 \\
\hline
\end{tabular}




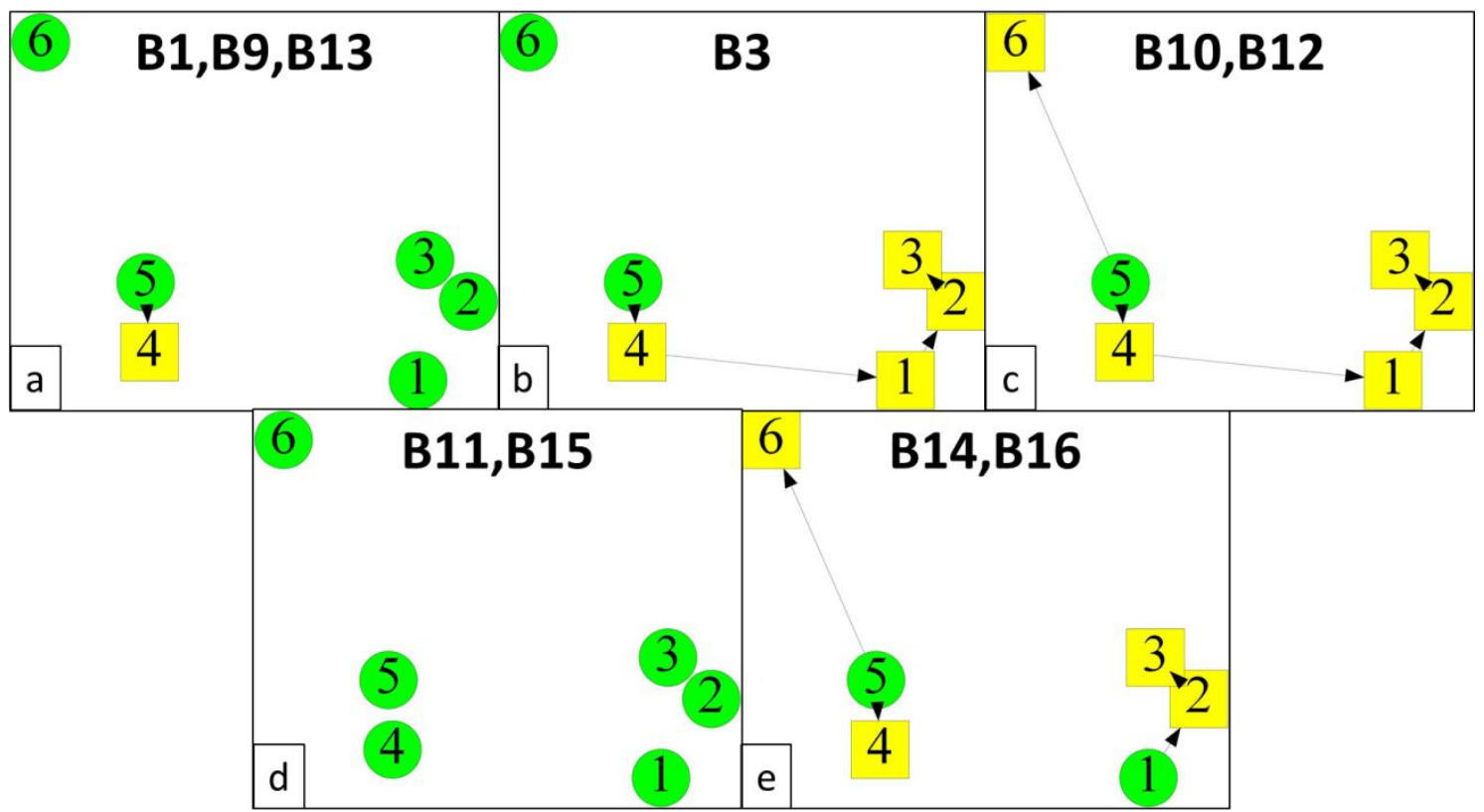

Fig. 6 - Distribution scheme of the alternative obtained at Stage 2, Level 2 (bis)

\section{Stage 2. System design. Level 3. Operational decisions. Cost vs Adequacy of equipment}

Different scenarios are studied for the two alternatives selected at Level 2. For the alternative B1, the decider proposes the next scenarios for the Adequacy of equipment:

- Minimum energy percentage generated by PV panels $\left(\mathrm{AT}_{2}\right) .1$ scenario: 0\%.

- Minimum number of generation equipment ( $\left.\mathrm{AT}_{3}\right) .2$ scenarios: 0 and 2.

- Additional energy percentage at individual users $\left(\mathrm{AT}_{4}\right) .1$ scenario: $0 \%$.

For the alternative B3, the decider proposes the next scenarios for the Adequacy of equipment:

- Minimum energy percentage generated by PV panels $\left(\mathrm{AT}_{2}\right) .1$ scenario: $0 \%$.

- Minimum number of generation equipment ( $\left.\mathrm{AT}_{3}\right) .2$ scenarios: 0 and 2 .

- Additional energy percentage at individual users (AT 4 ). 2 scenarios: 0 and $40 \%$.

Additionally, from Level 2 to Level 3, part of the solution is automatically fixed: the existing wires and their direction. The decider accepts to fix them, both for B1 and B3.

With these data, 6 electrification alternatives are obtained, 2 for the alternative B1 and 4 for the alternative B3. Table 10 shows their admissible and real values of the attributes. With the real values and the starting weights (Table 11) an $L_{F}(x)$ starting value is automatically calculated for each alternative (Table 10). Regarding the distribution scheme, no modifications in the configuration are obtained: the 2 alternatives from B1 have one two-user microgrid and four individual users (Fig. 6.a) and the 4 alternatives from B3 have one five-user microgrid and one individual users (Fig. 6.b). Therefore, the decider initially selects the best ranked alternative for each alternative from Level 2: C2 from B1 and C5 from B3. However, the decider observes that the alternative C4 and C5 have very similar indexes ( 0.397 and 0.395 , respectively) so selects both of them. 
Table 10 - Admissible and real values of the attributes, and $L_{F}(x)$ value for the alternatives of Stage 2, Level 3

\begin{tabular}{|c|c|c|c|c|c|c|c|}
\hline \multirow{2}{*}{\multicolumn{2}{|c|}{ Attributes }} & \multicolumn{2}{|c|}{ From B1 } & \multicolumn{4}{|c|}{ From B3 } \\
\hline & & $\mathrm{C1}$ & $\mathbf{C 2}$ & C3 & C4 & $\mathbf{C 5}$ & C6 \\
\hline \multirow{3}{*}{$\begin{array}{l}\text { Admissible } \\
\text { values }\end{array}$} & $\mathbf{A T}_{\mathbf{2}}$ & $0 \%$ & $0 \%$ & $0 \%$ & $0 \%$ & $0 \%$ & $0 \%$ \\
\hline & $\mathbf{A T}_{3}$ & 0 & 2 & 0 & 0 & 2 & 2 \\
\hline & $\mathbf{A T}_{4}$ & $0 \%$ & $0 \%$ & $0 \%$ & $40 \%$ & $0 \%$ & $40 \%$ \\
\hline \multirow{4}{*}{$\begin{array}{l}\text { Real } \\
\text { values }\end{array}$} & $\mathbf{R T}_{1}$ & 12033 & 12812 & 15518 & 16048 & 16000 & 16443 \\
\hline & $\mathbf{R T}_{2}$ & $0 \%$ & $0 \%$ & $0 \%$ & $0 \%$ & $0 \%$ & $0 \%$ \\
\hline & $\mathbf{R T}_{3}$ & 1 & 2 & 1 & 1 & 2 & 2 \\
\hline & $\mathbf{R T}_{4}$ & $1 \%$ & $1 \%$ & $26 \%$ & $67 \%$ & $5 \%$ & $67 \%$ \\
\hline \multicolumn{2}{|c|}{$L_{F}(x)$ (iteration 0$)$} & 0.533 & 0.467 & 0.442 & 0.397 & 0.395 & 0.467 \\
\hline
\end{tabular}

Table 11 - Weights of the criteria and subcriteria used at Stage 2, Level 3

\begin{tabular}{|l|l|l|l|}
\hline \multirow{2}{*}{ Criteria } & Weight & \multirow{2}{*}{ Subcriteria } & Weight \\
\cline { 2 - 4 } & Iteration 0 & & Iteration 0 \\
\hline $\mathbf{C T}_{1}$ & 0.47 & - & \\
\hline \multirow{3}{*}{$\mathbf{C T}_{2}$} & \multirow{3}{*}{0.53} & $\mathbf{C T}_{2-1}$ & 0.38 \\
\cline { 3 - 4 } & & $\mathbf{C T}_{2-2}$ & 0.30 \\
\cline { 3 - 4 } & $\mathbf{C T}_{2-3}$ & 0.32 \\
\hline
\end{tabular}

At this point, there are three candidate alternatives. To select one among them, the decider considers specific data from the target community. In particular, the decider selects $\mathrm{C} 4$ which: 1) has more microgrid users than $\mathrm{C} 2$ (Fig. 6.a and 6.b) that compensate the cost increase; and 2) offers a greater amount of energy to individual users than $\mathrm{C} 5$ for a similar cost (Table 8).

\section{Stage 3. Result improvement}

To conclude the design process, the decider tries to improve the cost of the alternative $\mathrm{C} 4$ selected at Stage 2, but maintaining the decisions taken. Table 12 shows the admissible and real values of the attributes of the three decision levels for the alternative $\mathrm{C} 4$ and the new obtained alternative $\mathrm{C} 4 *$. Moreover, Fig. 7 shows the electric distribution scheme of both alternatives. The main differences are: 1) the amount of energy and power supplied to the consumption points; 2) the distribution configuration, $\mathrm{C} 4$ having one five-user microgrid and $\mathrm{C} 4 *$ one three-user microgrid; and 3 ) the cost, that is a $22.4 \%$ lower for $\mathrm{C} 4 *$ than for $\mathrm{C} 4$. For that reason the decider selects $\mathrm{C} 4 *$.

Table 12 - Admissible and real values of the attributes for the alternatives studied at Stage 3

\begin{tabular}{|c|c|c|c|c|c|}
\hline & \multicolumn{5}{|c|}{ Attributes } \\
\hline & \multirow{2}{*}{\multicolumn{2}{|c|}{$\begin{array}{l}\text { Admissible } \\
\text { values }\end{array}$}} & \multicolumn{3}{|c|}{ Real values } \\
\hline & & & & C4 & C4* \\
\hline \multirow{3}{*}{ Level 1} & $\mathbf{A F}_{2}$ & $25 \%$ & $\mathbf{R F}_{2}$ & $58 \%$ & $72 \%$ \\
\hline & $\mathbf{A F}_{3}$ & $25 \%$ & $\mathbf{R F}_{3}$ & $42 \%$ & $28 \%$ \\
\hline & $\mathbf{A F}_{4}$ & $0 \%$ & $\mathbf{R F}_{4}$ & $1 \%$ & $3 \%$ \\
\hline \multirow{4}{*}{ Level 2} & $\mathbf{A S}_{2}$ & 1 & $\mathbf{R S}_{2}$ & 1 & 1 \\
\hline & $\mathbf{A S}_{\mathbf{3}}$ & 3 & $\mathbf{R S}_{\mathbf{3}}$ & 5 & 3 \\
\hline & $\mathbf{A S}_{\mathbf{4}}$ & 6 & $\mathbf{R S}_{4}$ & 1 & 3 \\
\hline & $\mathbf{A S}_{\mathbf{5}}$ & All & $\mathbf{R S}_{\mathbf{5}}$ & 6 & 6 \\
\hline \multirow{3}{*}{ Level 3} & $\mathbf{A T _ { 2 }}$ & $0 \%$ & $\mathbf{R T}_{2}$ & $0 \%$ & $0 \%$ \\
\hline & $\mathbf{A T}_{\mathbf{3}}$ & 0 & $\mathbf{R T}_{3}$ & 1 & 1 \\
\hline & $\mathbf{A T}_{4}$ & $40 \%$ & $\mathbf{R T}_{4}$ & $67 \%$ & $67 \%$ \\
\hline \multicolumn{4}{|l|}{ Cost [\$] } & 16048 & 12451 \\
\hline
\end{tabular}




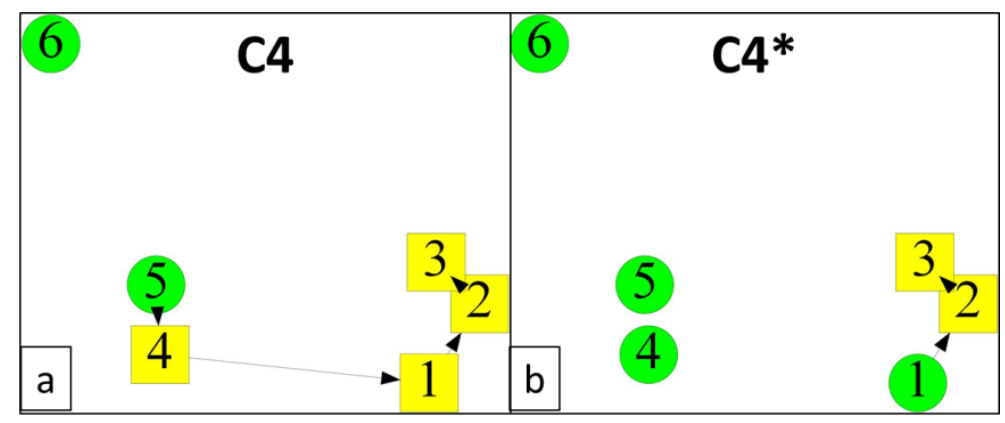

Fig. 7 - Distribution scheme of the alternative studied at Stage 3

\section{Conclusions}

This work aims to develop a methodology to design stand-alone electrification systems for rural communities, based on wind and PV energies and combining the distribution through microgrids and individual systems. Due to the complexity of the process, the design methodology is divided in three stages.

In Stage 1, three assessments allow identifying the input data for the next stages: the characteristics of the target community and the population. In Stage 2 the design process itself is carried out in three decision levels. Thus, the influence on the Cost of modifications on the Demand (Level 1), the Management of the system (Level 2) and the Adequacy of equipment (Level 3) are studied. Each level is structured in two steps: first a set of electrification alternatives is generated, using a mathematical model, and then the most appropriate one is selected, using the compromise programming. The whole process is complemented by two iterative procedures that allow studying many design options and adjusting users' preferences. Additionally, between one level and the next one, part of the solution can be fixed. A third and optional Stage is proposed to try to reduce the solution cost, maintaining the decisions taken previously.

Finally the functioning of the methodology is illustrated through its use by an expert to design the electrification system of a community. Results show how the methodology can assist electrification promoters to design stand-alone projects, trying many design options in a clear and structured framework and including economic, technical and social considerations. Besides, three demand scenarios are tried in Level 1, 16 management scenarios in Level 2 and 6 equipment adequacy scenarios in Level 3; many more scenarios than the usual 2 or 3 options considered when designing a project. Therefore, the appropriateness of the final solution is ensured, since it represents the best compromise between the minimum electrification cost and the maximum covered energy uses, the easiest management of the system and the better adequacy of equipment to population. As future research, two experts are currently using the methodology to design the projects for two real rural communities.

\section{Acknowledgements}

This paper was supported by the Centre of Cooperation for Development of the Universitat Politècnica de Catalunya (UPC). The authors are very grateful for all the assistance and support provided by the NGOs Practical Action (Peru), Engineering Without Borders (Catalonia, Spain), and Green Empowerment (USA). 


\section{Appendix A. Heuristic procedure based on the mathematical models}

Some previous computational experiments showed that the mathematical models shown in Section 4 allow obtaining near-to-optimal solutions in an adequate computing time $[33,35]$. However, when using the proposed methodology several alternatives are generated at each level, so the total calculation time can dramatically increase. For that reason, a heuristic procedure is needed to ensure that an acceptable solution is always found in a reduced calculation time. This solution could then be improved if the decider permits a longer calculation time.

The proposed heuristic consists of reducing the dimension of the problem to be solved. As introduced in Section 4, a maximum length of a wire segment of the microgrid is established by the decider as an input parameter for the mathematical models. This distance is now proposed to be substituted by a usually shorter one that depends on the cost of electrifying individually each point (see eq. A.1). Thus, the cheaper is a point's individual electrification cost, the shorter is its maximum connection distance to another point. The model using this new distance is from now on called "reduced model". Therefore, the complete heuristic procedure for each decision level is as follows: first the "reduced model" is solved in a maximum calculation time (which is detailed in Appendix B) and then the "non-reduced model" is solved trying to find, in the remaining calculation time, a cheaper solution including the previous cost as an upper bound. This process is applied to the three decision levels using the corresponding model (as explained in Section 4).

$$
L_{\text {max } \_i j} \leq \max \left(\frac{C_{\text {indiv_i }_{-}}}{C W} ; \frac{C_{\text {indiv_j }}}{C W}\right)
$$

where $L_{\text {max } \_i j}$ is the maximum connection distance between points $i$ and $j ; C_{\text {indiv } \_}$and $C_{i n d i v_{-} j}$ are the individual electrification costs of points $i$ and $j$; and $C W$ is the cost per meter of the cheapest wire.

It is worth to highlight that some incompatibilities can appear when solving the second decision level, depending on the decisions taken at Level 2. For example, if studying a maximum of 1 microgrid and 0 individual users, when combining both values a single microgrid should supply all the consumption points. However, if some points are too far from the others, the microgrid could not be compatible with the maximum connection distance $\left(L_{\text {max }} i j\right)$. In that case, instead of the "reduced model" an "alternative model" is solved. This "alternative model" finds an electric distribution configuration compatible with the problematic admissible values of the attributes (the single microgrid in the previous example), but without considering the generation and storage equipment.

\section{Appendix B. Validation of the alternatives generation step}

To validate the solution of the alternatives generation step of the three decision levels, two computational experiments are realized, evaluating the performance of the heuristic procedure and quantifying the error made when solving with the three levels in front of solving without them. For this purpose 20 instances are randomly generated based on a pattern of real communities, modifying most influencing elements on solutions: 
- The wind resource, the area and the orography of the terrain based on data from two real communities from the Andean highlands of Peru [33].

- The amount of consumption points: 10, 20, 30, 40 and 50.

- The concentration of the consumption points: $25 \%$ or $50 \%$ of the points concentrated in an area of the $30 \%$ of the analyzed region.

Moreover, the next admissible values of the attributes at each decision level were determined in collaboration with the NGOs Practical Action - Peru (PA), Engineering Without Borders - Spain (ESF) and Green Empowerment - USA (GE):

- Level 1. Demand.

Required energy $\left(\mathrm{AF}_{2}\right)$ and power $\left(\mathrm{AF}_{3}\right)$ by each point. 2 scenarios: $280 \mathrm{Wh} /$ day and $200 \mathrm{~W}$; and $420 \mathrm{Wh} /$ day and $300 \mathrm{~W}$.

Days of autonomy required $\left(\mathrm{AF}_{4}\right) .1$ scenario: 2 days.

- Level 2. Management of the system.

Maximum number of microgrids $\left(\mathrm{AS}_{2}\right) .2$ scenarios: not limited and 1.

Minimum number of users per microgrid $\left(\mathrm{AS}_{3}\right) .2$ scenarios: $0 \%$ and $25 \%$.

Maximum number of individual users $\left(\mathrm{AS}_{4}\right) .2$ scenarios: not limited and $25 \%$.

Meters at all the points or in microgrids $\left(\mathrm{AS}_{5}\right) .2$ scenarios: all and microgrid points.

- Adequacy of equipment.

Minimum energy percentage generated by PV panels $\left(\mathrm{AT}_{2}\right) .2$ scenarios: 0 and $25 \%$. Minimum number of generation equipment $\left(\mathrm{AT}_{3}\right) .2$ scenarios: 0 and 2.

Additional energy percentage at individual users ( $\left.\mathrm{AT}_{4}\right)$. 2scenarios: 0 and $20 \%$.

With this data, at the first level, two models are solved for each instance (the low and the high energy and power demands). At the second level 16 models should be solved for each instance; result of combining the two admissible values of each of the four attributes $\left(2^{4}=16\right)$. However two models are repeated and not considered: if imposing a maximum of 1 microgrid and a maximum of $25 \%$ of individual users, the solution is the same whether imposing or not a minimum of $25 \%$ of users per microgrid; both for the cases with meters at all the points or just at microgrid points. At the third level 8 models are solved for each instance; result of combining the two admissible values of each of the three attributes $\left(2^{3}=8\right)$. Therefore a total of 254 models are solved $(2+2 * 14+$ $2 * 14 * 8$ ) driving to 30 partial solutions (levels 1 and 2) and 224 final solutions (level 3).

\section{B.1. Computational experiment to evaluate the performance of the heuristic procedure}

To evaluate the performance of the heuristic rocedure, two different solving processes are compared. In both cases each instance is solved using the three decision levels, i.e. solving the 254 mathematical models:

- Resolution without heuristic (RNH). The proposed heuristic procedure is not used and at its place the "non-reduced model" is directly solved at each level.

- Resolution with heuristic (RH). The proposed heuristic procedure is used.

Before solving the models, the available calculation time needs to be distributed among the three decision levels. For this purpose, we consider an acceptable computing time of 3600s (as detailed next) and that the resolution of Level 1 is slower than Level 2, which 
is in turn slower than Level 3; since part of the solution is fixed between levels. Thus, the computing time is distributed as: $1800 \mathrm{~s}$ for each model from level 1, $1200 \mathrm{~s}$ for each model from level 2; and $600 \mathrm{~s}$ for each model from level 3. In this way, the maximum calculation time to solve each instance is around two days. Table B.1 shows the results for the three levels (the values represent the average for the 20 instances). First column shows the amount of models where RNH does not obtain any solution (RH always obtains a solution). Second column shows the cost difference between RH and $\mathrm{RNH}$. Negative values indicate a cost reduction using the heuristic while positive values indicate an increase. Finally, third column shows the percentage of solutions where RH obtains a cost better to or equal than RNH.

Table B.1 - Evaluation of the performance of the heuristic procedure

\begin{tabular}{|l|l|l|l|}
\cline { 2 - 4 } \multicolumn{1}{c|}{} & $\begin{array}{l}\text { RNH } \\
\text { non solved }\end{array}$ & $\begin{array}{l}\text { Mean } \\
\text { (RH-RNH) }\end{array}$ & $\begin{array}{l}\text { RH better to or } \\
\text { equal than RNH }\end{array}$ \\
\hline Level 1 & 0 & $0.0 \%$ & $72.5 \%$ \\
\hline Level 2 & 0 & $-0.9 \%$ & $79.3 \%$ \\
\hline Level 3 & 33 & $0.7 \%$ & $67.4 \%$ \\
\hline
\end{tabular}

As observed, if the heuristic procedure is not used, in 33 models from level 3 no solution is obtained. This is a key criterion to decide to use the heuristic, since the design methodology has to always find a solution. Moreover, in general terms, the costs obtained with and without the heuristic procedure are very similar, with differences lower than $1 \%$. Additionally, in more than two-third models the cost obtained using the heuristic procedure is equal to or lowers than without using it. Thus, results allow stating that the heuristic procedure obtains acceptable solutions.

\section{B.2. Computational experiment to quantify the error made when solving with the three decision levels}

To quantify the error made when solving the problem with the three levels in front of solving directly (once the admissible values of all attributes are proposed for the three levels, the models to solve without levels are generated; 224 in the current example), three solving processes are tested:

- Direct resolution (DR). Each instance is solved without decision levels, imposing a maximum calculation time of $3600 \mathrm{~s}$ for each of the 224 models, i.e. a total of 9 days and 8 hours per instance.

- Long levels resolution (LLR). Each instance is solved with the decision levels, imposing a maximum calculation time of $8481 \mathrm{~s}$ for each model of the first level, $5654 \mathrm{~s}$ for each model of the second level and $2827 \mathrm{~s}$ for each model of the third level (what corresponds to a total of $16962 \mathrm{~s}$ to solve the three models). These values also correspond to a total of 9 days and 8 hours per instance.

- Short levels resolution (SLR). Each instance is solved with decision levels, imposing a maximum calculation time of $1800 \mathrm{~s}$ for each model of the first level, $1200 \mathrm{~s}$ for each model of the second level and $600 \mathrm{~s}$ for each model of the third level. This is the RH (resolution with heuristic) form Section 4.3.1.

Table B. 2 shows the results obtained when comparing the direct resolution to the long and short levels resolutions (the values represent the average for the 20 instances). First 
and second columns respectively show the maximum percentage of cost reduction and increase, among the 224 final solutions with the levels resolution (xLR, LLR for long and SLR for short) in front of DR. Third column shows the average cost difference obtained by xLR in front of DR. The positive values indicate a cost increase using the three levels. Finally, fourth column shows the percentage of solutions where the cost obtained with xLR is better to or equal than with DR.

Table B.2 - Experiment to quantify the error made when solving with the three decision levels

\begin{tabular}{|l|l|l|l|l|}
\cline { 2 - 5 } \multicolumn{1}{c|}{} & $\begin{array}{l}\text { Max_red } \\
\text { (xLR-DR) }\end{array}$ & $\begin{array}{l}\text { Max_inc }_{224} \\
\text { (xLR-DR) }\end{array}$ & $\begin{array}{l}\text { Mean } \\
\text { (xLR-DR) }\end{array}$ & $\begin{array}{l}\text { xLR better to or } \\
\text { equal than DR }\end{array}$ \\
\hline LLR & $18.3 \%$ & $61.1 \%$ & $0.7 \%$ & $54.4 \%$ \\
\hline SLR & $18.4 \%$ & $61.1 \%$ & $0.9 \%$ & $52.2 \%$ \\
\hline
\end{tabular}

As observed, in general terms the cost obtained when solving with decision levels is less than $1 \%$ worse than the cost obtained when solving directly. Besides, in most cases the cost using decision levels is better than or equal to the cost without levels. Moreover, although for some cases the maximum cost increase is significantly high (attaining $61.1 \%$ ), these are punctual cases, caused by the randomized and generalized studied admissible values of the attributes, without a detailed analysis for each instance. Additionally, it is worth to highlight that allowing more calculation time for the levels resolution (LLR vs. SLR) does not lead to significantly better results. Therefore, the short level resolution is proposed to be used since it obtains similar results than the direct resolution but in a lower calculation time. This strengthens the idea of working with decision levels, which mainly allow the decider to interact and structure the decision-making to adjust the design to the real needs of population.

\section{References}

[1] IEA, International Energy Agency. World Energy Outlook. Paris; 2013.

[2] Kanagawa M, Nakata T. Assessment of access to electricity and the socio-economic impacts in rural areas of developing countries. Energy Policy 2008; 36:2016-29.

[3] Chaurey A, Ranganathana M, Mohanty P. Electricity access for geographically disadvantaged rural communities - technology and policy insights. Energy Policy 2004; 32:1693-705.

[4] Elma E, Selamogullari US. A comparative sizing analysis of a renewable energy supplied standalone house considering both demand side and source side dynamics. Appl Energy 2012; 96:400-8.

[5] Ferrer-Martí L, Garwood A, Chiroque J, Ramírez B, Marcelo O, Garfí M, Velo E. Evaluating and comparing three community small-scale wind electrification projects. Renew Sustain Energy Rev 2012; 16:5379-90.

[6] Kirubi C, Jacobson A, Kammen DM, Mills A. Community-based electric micro-grids can contribute to rural development: Evidence from Kenya. World Dev 2009; 37:1208-21.

[7] Yadoo A, Cruickshank H. The role for low carbon electrification technologies in poverty reduction and climate change strategies: A focus on renewable energy mini-grids with case studies in Nepal, Peru and Kenya. Energy Policy 2012; 42:591-602.

[8] Schäfer M, Kebir N, Neumann K. Research needs for meeting the challenge of decentralized energy supply in developing countries. Energy Sustain Dev 2011; 15:324-9.

[9] Rahman M, Paatero JV, Lahdelma R. Evaluation of choices for sustainable rural electrification in developing countries: A multicriteria approach. Energy Policy 2013; 59:589-99.

[10] Rojas-Zerpa JC, Yusta JM. Methodologies, technologies and applications for electric supply planning in rural remote areas. Energy Sustain Dev 2014; 20:66-76.

[11] Gupta CL. Role of renewable energy technologies in generating sustainable livelihoods. Renew Sustain Energy Rev 2003; 7:155-74.

[12] Fernández-Baldor A, Boni A, Lillo P, Hueso A. Are technological projects reducing social inequalities and improving people's well-being? A capability approach analysis of renewable 
energy-based electrification projects in Cajamarca, Peru. J Hum Dev Capab: A Multi-Disciplinary Journal for People-Centered Development 2014; 15:13-27.

[13] Domenech B, Ferrer-Martí L, Lillo P, Chiroque J, Pastor R. A community electrification project: Combination of microgrids and household systems fed by wind, PV or micro-hydro energies according to micro-scale resource evaluation and social constraints. Energy Sustain Dev 2014; 23:275-85.

[14] Alarcón-Rodriguez A, Ault G, Galloway S. Multi-objective planning of distributed energy resources: A review of the state-of-the-art. Renewable \& Sustainable Energy Reviews 2010; 14:1353-66.

[15] Savic D. Single-objective vs. multi-objective optimization for integrated decision support. In: Proceedings of the first biennial meeting of the international environment modeling and software society $2007 ; 1: 7-12$.

[16] Keller S, Naciri S, Nejmi A, Dos Ghali J. Simulation-based decision support tool for electrification of isolated areas using a network with multiple renewable sources. Int Conf Clean Electr Power 2007.

[17] Cherni JA, Dyner I, Henao F, Jaramillo P, Smith R, Olade R. Energy supply for sustainable rural livelihoods. A multi-criteria decision-support system. Energy Policy 2007; 35:1493-504.

[18] Henao F, Cherni JA, Jaramillo P, Dyner I. A multicriteria approach to sustainable energy supply for the rural poor. Eur J Oper Res 2012; 218:801-9.

[19] Perera ATD, Attalage RA, Perera KKCK, Dassanayake VPC. A hybrid tool to combine multiobjective optimization and multi-criterion decision making in designing standalone hybrid energy systems. Appl Energy 2013; 107:412-25.

[20] Zhou W, Lou C, Li Z, Lu L, Yang H. Current status of research on optimum sizing of stand-alone hybrid solar-wind power generation systems. Appl Energy 2010; 87:380-9.

[21] Mendes G, Ioakimidis C, Ferrao P. On the planning and analysis of integrated community energy systems: A review and survey of available tools. Renew Sustain Energy Rev 2011; 15:4836- 54.

[22] Bhattacharyya SC. Review of alternative methodologies for analyzing off-grid electricity supply. Renew Sustain Energy Rev 2012; 16:677-94.

[23] Erdinc O, Uzunoglu M. Optimum design of hybrid renewable energy systems: Overview of different approaches. Renew Sustain Energy Rev 2012; 16:1412-25.

[24] Luna-Rubio R, Trejo-Perea M, Vargas-Vázquez D, Ríos-Moreno GJ. Optimal sizing of renewable hybrids energy systems: A review of methodologies. Sol Energy 2012; 86:1077-88.

[25] Akella AK, Sharma MP, Saini RP. Optimum utilization of renewable energy sources in a remote area. Renew Sustain Energy Rev 2007; 11:894-908.

[26] Lambert TW, Hittle DC. Optimization of autonomous village electrification systems by simulated annealing. Sol Energy 2000; 68:121-32.

[27] Karger CR, Hennings W. Sustainability evaluation of decentralized generation. Renew Sustain Energy Rev 2009; 13:583-93.

[28] Wang JJ, Jing YY, Zhang CF, Zhao JH. Review on multi-criteria decision analysis aid in sustainable energy decision-making. Renew Sustain Energy Rev 2009; 13:2263-78.

[29] Pohekar SD, Ramachandran M. Application of multi-criteria decision making to sustainable energy planning - A review. Renew Sustain Energy Rev 2004; 8:365-81.

[30] Zhou P, Ang BW, Poh KL. Decision analysis in energy and environmental modeling: An update. Energy 2006; 31:2604-22.

[31] Loken E. Use of multicriteria decision analysis methods for energy planning problems. Renew Sustain Energy Rev 2007; 11:1584-95.

[32] Thery R, Zarate P. Energy planning: A multi-level and multicriteria decision making structure proposal. Cent Eur J Oper Res 2009; 17:265-74.

[33] Ferrer-Martí L, Domenech B, García-Villoria A, Pastor R. A MILP model to design hybridphotovoltaic isolated rural electrification projects in developing countries. Eur J Oper Res 2013; 226:293-300.

[34] Frearson L, Tuckwell M. The future of mini-grids: from low cost to high value. Using demand driven design to maximize revenue and impact. Asian Development Bank. Manila; 2013.

[35] Domenech B, Ferrer-Martí L, Pastor R. Including social constraints for designing stand-alone electrification systems in developing countries. Renewable Energy (submitted).

[36] Gueymard CA, Wilcox SM. Assessment of spatial and temporal variability in the US solar resource from radiometric measurements and predictions from models using ground-based or satellite data. Sol Energy 2011; 85:1068-84. 
[37] Ranaboldo M, Ferrer-Martí L, Velo E. Micro-scale wind resource assessment for off-grid electrification projects in rural communities. A case study in Peru. Int J Green Energy 2014; 11:75-90.

[38] Landberg L, Myllerup L, Rathmann O, Petersen EL, Jorgensen BH, Badger J, Mortensen NG. Wind resource estimation - An overview. Ris $\emptyset$ National Laboratory. Wind Energy 2003; 6:261-71.

[39] Ashok S. Optimized model for community-based hybrid energy system. Renew Energy 2007; 32:1155-64.

[40] Baños R, Manzano-Agugliaro F, Montoya FG, Gil C, Alcayde A, Gómez J. Optimization methods applied to renewable and sustainable energy: a review. Renew Sustain Energy Rev 2011; 15:1753-66.

[41] Georgopoulou E, Lalas D, Papagiannakis L. A Multicriteria decision aid approach for energy planning problems: The case of renewable energy option. Eur J Oper Res 1997; 103:38-54.

[42] Afgan NH, Carvalho MG, Hovanov NV. Energy system assessment with sustainability indicators. Energy Policy 2000; 28:603-12.

[43] Biswas WK, Bryce P, Diesendorf M. Model for empowering rural poor through renewable energy technologies in Bangladesh. Environ Sci Policy 2001; 4:333-44.

[44] Saaty TL. The analytic hierarchy process. Wiley. New York; 1980.

[45] Yu PL. A class of solution for group decision problem. Manag Sci 1973; 19:936-46.

[46] Zeleny M. Compromise programming. Multiple criteria decision making. University of South Carolina Press. Columbia; 1973; pp. 263-301.

[47] Zeleny M. A concept of compromise solutions and the method of the displaced ideals. Computers Oper Res 1974; 1:479-96.

[48] Eppel T. Description and procedure invariance in multiattribute utility measurement. School of Management, Purdue Univ., West Lafayette, IN; 1992.

[49] Nijkamp P, Reitveld P, Voogd H. Multicriteria Evaluation in Physical Planning. Elsevier Science. North Holland, Amsterdam; 1990.

[50] Hashimoto A, Wu DA. A DEA-compromise programming model for comprehensive ranking. J Oper Res Jpn 2004; 47:73-81.

[51] Diaz-Balteiro L, Romero C. In search of a natural systems sustainability index. Ecological Economics 2004; 49:401-5.

[52] San Cristóbal JR. Multi-criteria decision-making in the selection of a renewable energy project in Spain: The VIKOR method. Renew Energy 2011; 36:498-502.

[53] NASA Surface meteorology and Solar Energy, Release 6.0 Version 3.0, April 2011. http://eosweb.larc.nasa.gov/sse/. Accessed 27th of March 2012. 